\title{
A CIGARRA, A FORMIGA E A AQUISIÇÃO DE OBRAS DE ARTE PELO PODER PÚBLICO
}

\author{
MARCílio TOSCANo FranCA FiLHo
}

\author{
I. À Guisa de Introdução. II. A Legitimidade do Investimento Público \\ em Arte. III. As Vias Procedimentais Legalmente Admitidas. IV. A Via \\ Procedimental Eleita
}

\section{I. À Guisa de Introdução}

Há alguns meses o Tribunal de Justiça do Estado decidiu adquirir dois grandes quadros em acrílico sobre tela, medindo $2,20 \mathrm{~m} \times 1,40 \mathrm{~m}$ cada, de autoria do pintor paraibano contemporâneo FLÁVIO TAVARES, a fim de adornarem o Tribunal do Júri da capital. Para tanto, o Tribunal valeu-se de um procedimento de inexigibilidade de licitação.

A conduta adotada pela Corte estadual, de compra direta das telas ao seu autor, sem licitação, não restou imune a algumas críticas sobre a legitimidade e a forma daquela aquisição. As considerações ora trazidas à baila pretendem jogar algumas luzes sobre o tema dos limites da discricionariedade administrativa, sobretudo quando vinculada à aquisição de artes plásticas.

1 O autor é Procurador do Ministério Público junto ao Tribunal de Contas da Paraíba, Mestre em Ciências Jurídicas (UFPB/1999) e Doutorando em Direito Comunitário (Universidade de Coimbra). Foi Professor do Departamento de Direito Público da Universidade Federal da Paraíba, aluno da Universidade Livre de Berlim (Alemanha) e estagiário do Tribunal de Justiça das Comunidades Européias (Luxemburgo). É um dever do autor registrar os seus mais sinceros agradecimentos à Profa. Ms. Maria das Neves Franca, que, dedicada ao mundo da filosofia com singular competência, possibilitou um profícuo debate sobre a arte e o seu papel, cuja importância foi capital para o aperfeiçoamento das idéias expostas neste breve artigo. 
Há cerca de pouco mais de dois séculos, quando arte e artistas perdiam muitas das suas atribuições junto ao Estado e à Igreja, HEGEL entendeu que a arte havia desempenhado a sua função e, assim, colocou o futuro da obra de arte em dúvida. As declarações hegelianas levaram alguns seguidores mais radicais da tradição do racionalismo iluminista alemão a sentenciar a morte da arte. Na verdade, desde que o senso comum passou a enxergar na razão humana a única medida de todas as coisas, o desprestígio da arte só fez se acentuar. Não por acaso, nas cortes francesas do despotismo esclarecido, fazia sucesso entre os nobres a triste fábula da cigarra e da formiga, imortalizada nos versos de JEAN DE LA FONTAINE:

\section{A CIGARRA E A FORMIGA}

Tendo a cigarra em cantigas

Folgado todo o verão,

Achou-se em penúria extrema

Na tormentosa estação.

Não the restando migalha

Que trincasse, a tagarela

Foi valer-se da formiga,

Que morava perto dela.

Rogou-lhe que lhe emprestasse,

Pois tinha riqueza e brio,

Algum grão com que manter-se

Té voltar o aceso estio.

A formiga nunca empresta,

Nunca dá, por isso junta.

"No verão em que lidavas?"

$\grave{A}$ pedinte ela pergunta.

Responde a outra: "Eu cantava

Noite e dia, a toda hora.

- Oh! Bravo! - tornou a formiga -

Cantavas? Pois dança agora!" 2

O império da velocidade, as certezas inabaláveis, a Revolução Industrial, as linhas de produção fordistas e o ostracismo dos ofícios manuais apenas contribuíram

2 LA FONTAINE, Jean de. "A Cigarra e a Formiga." Trad. de Bocage. In: Fábulas. São Paulo: Landy, 2003, pp. 11-12. 
para o menosprezo da obra de arte depois do século XIX e para a sua identificação com o ócio. Coincidentemente, já no início do século $\mathrm{XX}$, os futuristas italianos exigiam a destruição dos museus e os dadaístas - logo depois - queriam abolir a "arte". Na mesma direção, surgiu, a partir de então, uma profusão de manifestos de "vanguardas" antiarte ou defendendo uma não-arte.

A arte não modifica o mundo como uma ferramenta mas tem a sua magnitude. A grandeza da arte reside na impossibilidade de sua redução a uma representação efêmera do presente e do real - seja por razões ideológicas, pedagógicas, hedonísticas ou religiosas. Nesse sentido, vale lembrar a meditação do filósofo MARTIN HEIDEGGER sobre a arte e sua origem. No ensaio intitulado A Origem da Obra de Arte $^{3}$, fruto de três conferências realizadas em 1936, o pensador alemão faz uma exegese dos "sapatos camponeses" presentes na obra de VAN GOGH, desvelando a instrumentalidade dos sapatos e mostrando que ali isto - a instrumentalidade se expressa como nenhum exame de sapatos reais poderia fazer surgir. Veja-se a descrição de HEIDEGGER:

$\mathrm{Na}$ escura abertura do interior gasto dos sapatos, fita-nos a dificuldade e o cansaço dos passos do trabalhador. (...) No couro está a umidade e a fertilidade do solo. (...) Por este apetrecho passa o calado temor pela segurança do pão, a silenciosa alegria de vencer uma vez mais a miséria. (...) Este apetrecho pertence à terra e está abrigado no mundo da camponesa (p. 25).

A obra de arte difere, pois, de qualquer outra coisa. Por quê? Porque nela acontece uma abertura que revela o ser das coisas. É, portanto, na mentira da arte que se pode encontrar a verdade mais consistente.

Sabendo-se disso, é preciso, antes de tudo, louvar intensamente o investimento do Tribunal de Justiça da Paraíba. Em um mundo de pressa e de repartições públicas construídas com divisórias de madeira e blocos pré-moldados, é salutar que um órgão do Estado preocupe-se com a perenidade da arte. Sobretudo quando essa preocupação estatal encontra-se desapegada de qualquer controle burocrático dos destinos e fins da arte subvencionada/adquirida e mais ainda quando se está em uma cidade onde ainda são poucas as pinacotecas públicas.

Dito isso, é preciso examinar agora se os caminhos procedimentais escolhidos pelo Tribunal de Justiça da Paraíba para a aquisição das duas telas encontram ou não respaldo legal no mundo do Direito.

\section{As Vias Procedimentais Legalmente Admitidas}

Segundo a Lei de Licitações (Lei 8.666/93), dois são os caminhos possíveis para a Administração Pública contratar a aquisição de uma tela ou uma escultura de um artista plástico, quais sejam:

3 HEIDEGGER, Martin. A Origem da Obra de Arte. Trad. de Mana Conceição Costa. Lisboa: Ediçōes 70, 1991. 
1) O concurso (disciplinado pelo art. $22, \S 4^{\circ}$, da Lei $\left.8.666 / 93\right)^{4}$ ou

2) A inexigibilidade de licitação (regrada pelo art. 25 , inc. III, da Lei $8.666 / 93)^{5}$.

No concurso, um dos fins da atuação estatal é certamente o de promover a visibilidade efetiva de um produto artístico ou seu autor - nem tão conhecidos à partida. Para legitimar uma tal política de visibilidade, o Estado recorre a uma comissão julgadora soberana, que tem como tarefa prioritária institucionalizar um top ten oficial de obras de arte que são comparadas de acordo com padrões formais compatíveis com o que ela, a Comissão, julga o que deve ser a arte. Tarefa sem dúvida complexa a desse "Estado estético".

De outro lado, a inexigibilidade de licitação na aquisição de obra de arte tem por escopo a incorporação ao patrimônio estatal de um trabalho artístico de autor já consagrado por meio de uma contratação direta. Nesses casos, fica ao falante da Administração definir sobre quem ou o que recairá a aquisição sem licitação. As exigências extraídas da legislação dizem respeito apenas à consagração do artista pela crítica especializada ou pela opinião pública, além da observância dos princípios constitucionais da impessoalidade, moralidade, publicidade, economicidade, razoabilidade e proporcionalidade.

A opção do Administrador Público entre a realização de um concurso ou a aquisição direta mediante a inexigibilidade de licitação circunscreve-se naquilo que a melhor doutrina administrativa chamou de Poder Discricionário (Discretion, em inglês; Ermessen, em alemão; Pouvoir discrétionnaire, em francês), ou seja, a faculdade de que dispõe o gestor público para a ponderação de interesses, oportunidades e conveniências que preenche uma norma legal aberta, autorizativa de uma decisão.

Segundo a didática lição da dogmática alemã, o conceito de Poder Discricionário diz respeito à pluralidade de consequiências jurídicas admitidas por uma norma legal. Veja-se:

Apesar de serem vinculadas pelo Direito, as autoridades administrativas são beneficiadas com certa margem de discricionariedade (Ermessen) quando tomam decisões. Assim, algumas provisões legais permitirão a elas liberdade a respeito de se ou como reagir a certas situações. (...) A maioria das provisões legais pode ser caracterizada como "cláusulas se-então". Se uma certa situação se manifesta, então uma certa consequiência legal se segue. Essas consequiências legais em Direito Administrativo incluem as competências para agir das autoridades administrativas. A discricionariedade é

4 " $\$ 4^{\circ}$. Concurso é a modalidade de licitação entre quaisquer interessados para escolha de trabalho técnico, científico ou artístico, mediante a instituição de prêmios ou remuneração aos vencedores, conforme critérios constantes de edital publicado na imprensa oficial com antecedência mínima de 45 (quarenta e cinco) dias."

5 "Art. 25. É inexigível a licitação quando houver inviabilidade de competição, em especial: (...) III - para contrataçāo de profissional de qualquer setor artístico, diretamente ou através de empresário exclusivo, desde que consagrado pela crítica especializada ou pela opinião pública." 
conferida para a parte concernente às consequiências legais da provisão, em outras palavras, para o lado "então" daquela provisão legal. ${ }^{6}$

A se seguir o esquema teórico proposto pelos Professores FOSTER e SULE, tem-se que SE (if) o Estado quer adquirir uma obra de arte, ENTÃO (then) ele pode valer-se de um concurso ou de uma inexigibilidade licitatória - conforme a margem de liberdade conferida pela Lei de Licitações. Presente a pluralidade de soluções ou consequiências, configurada resta portanto a legítima discricionariedade da autoridade judiciária em escolher uma ou outra saída. Não é outra a razão porque o Prof. RENÉ CHAPUS, maior expoente da doutrina administrativa francesa contemporânea, identifica o Poder Discricionário com um "poder de escolha entre duas decisões ou dois comportamentos (dois pelo menos), todos igualmente conformes à legalidade"?

A vinculação do Poder Discricionário aos limites da legalidade há de ser sempre observada, sob pena de invalidação do ato que transborda as margens da lei: "a discricionariedade é limitada pelo legislador", ensinou o Prof. HARTMUT MAURER. $^{8}$

Uma vez que, diante das opções legalmente possíveis, a autoridade judiciária optou legitimamente pela realização de uma contratação direta mediante inexigibilidade licitatória, cumpre examinar então se a moldura institucional desse permissivo foi respeitada.

\section{A Via Procedimental Eleita}

Após uma breve análise do mencionado art. 25, inc. III, da Lei 8.666/93, percebe-se que o requisito indispensável para regular a contratação, através de inexigibilidade de licitação, da compra de uma obra de arte é a consagração do artista pela crítica especializada ou pela opinião pública - segundo os exatos termos da lei. Nesse diapasão, ensina o mestre HELLY LOPES:

6 "In Spite of being bound by the law, administrative authorities are granted a certain degree of discretion (Ermessen) when making decisions. Thus some legal provisions will allow them discretion as to whether or how to react to certain situations. (...) Most legal provisions can be characterized as 'if-then clauses'. If a certain situation manifests, then a certain legal consequence follows. These legal consequences in administrative law include the authorities' competence to act. Discretion is provided for in the part concerning the legal consequences of the provision, in other words the 'ther-side of the provision"' (FOSTER, Nigel; SULE, Satish. German Legal System and Laws. Oxford: Oxford University Press, 2003, p. 255, trad. nossa).

7 "Le pouvoir discrétionnaire des autorités administratives n'est rien d'autre que le pouvoir de choisir entre deux decisions ou deux comportements (deux au moins) également conformes à la légalité' (CHAPUS, René. Droit Administratif Général. Tomo 1. Paris: Montchrestien, 2001, p. 1056, trad. nossa).

8 "Das Ermessen wird durch den Gesetzgeber eingeräumt" (MAURER, Hartmut. Allgemeines Verwaltungsrecht. Munique: C. H. Beck, 2000, p. 125, trad. nossa). 
O essencial para legitimar a dispensa do procedimento licitatórío é que o artista seja consagrado pela crítica especializada ou pela opinião pública" ${ }^{9}$.

As noções de "consagração", "crítica especializada" e "opinião pública” são conceitos jurídicos indeterminados, ou seja, termos extrajurídicos, abertos, polissêmicos, cujo sentido e alcance são preenchidos pela margem de apreciação (Beurteilungsspielraum) da autoridade administrativa ao ponderar as circunstâncias do caso concreto, mas nem por isso livres da esfera de controle externo exercida pelo Tribunal de Contas à luz da impessoalidade, moralidade, publicidade, economicidade, razoabilidade e proporcionalidade.

Mais uma vez, há de se recorrer às didáticas lições dos Professores FOSTER e SULE para se clarificar o que seja essa "margem de apreciação" do administrador:

O princípio da discricionariedade é atribuído para aquela parte das provisões legais que dizem respeito às conseqüências de um conjunto de fatos. A margem de apreciação (Beurteilungsspielraum), em contraste, refere-se àquela parte das provisões legais que definem fatos como precondições para consequiências legais, em outras palavras, o lado "se" da clausula "se-então". Aqui o Legislativo utilizou conceitos jurídicos indeterminados (unbestimmte Rechtsbegriffe) tais como "interesse público", "contabilidade suficiente" (para iniciar uma relação comercial) ou "de boa moral". Tais termos concedem às autoridades administrativas uma oportunidade para julgar se a situação descrita em uma provisão esta à mão ou não. (...) Se o Legislativo concede às autoridades administrativas esta margem de apreciação, então a questão que aflora é se os tribunais podem subseqüentemente revê-la. (...) O Tribunal Administrativo Federal tanto quanto o Tribunal Constitucional Federal têm decidido que os tribunais administrativos têm geralmente o poder e a obrigação para apreciar completamente as decisões administrativas. Não obstante, como uma exceção algumas poucas áreas são excluídas dessa "revisão total", tais como decisões concernentes a provas (exames escolares e decisões semelhantes, exames de ordem), concursos públicos, decisões de classificação por comitês independentes ou decisões de prognósticos de risco. ${ }^{10}$

9 MEIRELLES, Hely Lopes. Licitação e Contrato Administrativo. $11^{\text {a }}$ ed. São Paulo: Malheiros, 1996. p. 99.

10 "The principle of discretion is attributed to that part of the provisions dealing with the legal consequences of a set of facts. The margin of appreciation (Beurteilungsspielraum) in contrast applies to the part of the provision setting out the facts as preconditions to legal consequences, in other words the 'if'-side of the 'if-then' clause. Here the legislative has used indefinite legal terms (unbestimmte Rechtsbegriffe) such as the 'public interests', 'sufficent reliability' (to run a commercial enterprise), or 'against good morals'. These terms grant the authorities an opportunity to judge for themselves whether the situation described in a provision is at hand or not. (...) If the legislative grants administrative authorities this margin of appreciation, then the question arises whether the courts may subsequently review it. (...) The Federal Administrative Court and the Federal Constitutional Court have decided that the administrative courts generally the power and obligation to 
A se seguir, novamente, o esquema teórico proposto por FOSTER e SULE, tem-se que SE (if) o artista é consagrado pela opinião pública ou pela crítica especializada, ENTÃO (then) a Administração Pública pode fazer uso de uma inexigibilidade licitatória. Presente aquele pré-requisito fático ("consagração pela crítica especializada ou pela opinião pública"), legitimada estará a ausência de licitação.

Quanto aos conceitos jurídicos indeterminados, que deixam à Administração Pública uma certa margem da apreciação, o controle externo é ainda mais trabalhoso do que no caso de decisões discricionárias. À primeira vista, a autoridade administrativa deve apresentar ao Controller todos os elementos que subsidiaram as suas reflexões e considerações que a trouxeram à interpretação e à aplicação dos conceitos jurídicos indeterminados. Desse modo, o Controller pode examinar se a decisão está amparada por razões plausíveis, razoáveis, proporcionais, isto é, legítimas. Não é o caso de se substituir a interpretação da Administração por outra, mas apenas de se examinar a razoabilidade e a adequação das razões que a Administração apresentou. ${ }^{1 \prime}$

A questão que se impõe agora é, portanto, a de saber se o artista plástico FLÁ VIO TAVARES é consagrado pela opinião pública ou crítica especializada - sobretudo à luz dos princípios constitucionais da impessoalidade, moralidade, publicidade, razoabilidade e proporcionalidade.

Quanto a isso, é preciso sublinhar, em primeiro lugar, que o Tribunal de Justiça não se preocupou em demonstrar em parte alguma dos autos daquele procedimento de inexigibilidade licitatória que o artista plástico FLÁVIO TAVARES é consagrado pela opinião pública e pela crítica especializada. Mas precisaria tê-lo feito? Em outras palavras: estava o Tribunal de Justiça obrigado a comprovar que o artista plástico cujas telas comprou sem licitação é consagrado pela opinião pública e pela crítica especializada? Entendemos que não. O Tribunal de Justiça não tinha esse dever de comprovação. $\mathrm{Na}$ verdade, exigir provas de que alguém é consagrado pela crítica ou pelo público é criar um verdadeiro paradoxo, pois se o artista contratado é de fato "consagrado" deve ser conhecido de todos; se ele não é conhecido de todos, ele ainda não é consagrado. $O$ argumento é de clareza acaciana ${ }^{12}$ : não há consagração

completely review administrative decisions. (...) Nevertheless as an exception a few areas are excluded from 'total review', such as decisions concerning exams (school exams and related decisions, state exams), assessments of civil servants, rating decisions by independent committees or prognostic decisions of risks" (FOSTER \& SULE, op. cit., pp. 256-257, trad. nossa).

11 Por todos, FISCHER, Alfred. "Rapport pour l'Allemagne Federale". In: Anales du 5e Colloque de l'Association des Conseils d'Etat et des Juridictions Administratives Suprêmes de I'Union Européenne (de 27 a 31 de outubro 1976 em Haia). Disponível em http://193.191.217.21/colloquia/1976/germany.pdf.

12 No imaginário queirosiano de $O$ Primo Basilio, o Conselheiro Acácio veio a transformar-se numa daquelas personagens que retornam para o mundo real. Pensando decerto neste burocrata para quem as "curiosidades" do Alentejo eram "de primeira ordem", Eça de Queirós referiu-se várias vezes a ele, quando quis aludir à solenidade oca e às obviedades que marcavam a sociedade portuguesa de então. Era o lugar-comum em pessoa. Longe estava Eça de saber que a língua portuguesa havia de cunhar o adjetivo "acaciano", precisamente derivado do nome da criatura que por ele nos foi legada. 
que não evidente; a verdadeira consagração pública há de ser notória e os fatos notórios prescindem de comprovação (art. 334, 1, do Código de Processo Civil). Atente-se que o sentido de "todos" aqui não é numérico, mas na verdade representa tão-só o "sensato juízo do homem médio" ou, segundo a boa expressão da jurisprudência alemã, o "vernünftige Urteil der billig und gerecht Denkenden".

Toma-se aqui "consagração", do latim consacratione, como a honra, a exaltação, a glorificação, o louvor, o elogio ou o aplauso manifestado pelo público ou pela crítica. Tais atributos são enxergados com facilidade no pintor paraibano FLÁVIO TAVARES e em sua obra, cujo prestígio nacional e internacional podem ser aferidos nas críticas insertas no catálogo de sua exposição "Canteiros da Memória", exibida, entre outros, no Museu de Arte Moderna da Bahia (MAM/BA), de 30 de outubro a 14 de novembro de 1998. A seguir, alguns trechos daquelas críticas:

UM PINTOR BEM BRASILEIRO - Faz mais de vinte anos que entrei pela primeira vez no atelier de Flávio Tavares. Impressionou-me a força gráfica concentrada dos seus trabalhos em papel e as expressivas pinturas a óleo. Nos seus desenhos, cavaleiros e burgueses faziam festas orgíacas, emolduradas por animais e por personagens de fábulas. Como tema central de seus quadros a óleo, havia mulheres belas, dominadoras de homens e animais, num mundo tropical. Muitos anos depois, ao ler "A pedra do reino", de Ariano Suassuna, eu os encontrei novamente: os cavaleiros, os personagens de fábula e as mulheres do sertão. No ano de 1981, e até hoje, expus e exponho os trabalhos de Flávio Tavares na Alemanha. Grande é a repercussão. Visitantes e críticos das exposições ressaltam que Tavares é um pintor originalmente brasileiro, que não caiu na mesmice da arte mundial, mas que permanece fiel às suas origens e não nega suas raízes. Nessa autenticidade encontra-se sua força e, com Suassuna, ele estende o arco dos cavaleiros do sertão à Europa medieval. Flávio Tavares é um pintor brasileiro de quem podemos nos orgulhar.

MARIA DO CARMO VOGT - Presidente da DBKV - Deutsch-Brasilianische Kulturelle Vereinigung e. V.

ATIÇANDO LEMBRANÇAS - (...) Mestre exímio do desenho e da pintura, depois de conseguir grandes proezas com a sua arte nas grandes cidades do Primeiro Mundo, Flávio resolve voltar-se para dentro de si mesmo para de lá retirar tudo de belo, de pitoresco, que seus olhos de menino captaram. São lembranças instigantes e cada tela relata uma situação diferente que nos faz compreender como se vivia naquela época. As tardes deliciosas passadas nos jardins e quintais do bairro sempre alimentaram sua imaginação, e assim nessa mostra de Flávio Tavares continua o desfile de imagens emblemáticas de um tempo que não volta mais e mesmo assim continua atiçando nossas lembranças.

EUDES ROCHA - Da Associação Brasileira de Críticos de Arte e da Associação Internacional de Críticos de Arte. 
EXPRESSAR-SE - (...) Flávio Tavares não precisa de apresentações. Ainda criança aprendeu a se encantar com as imagens que nos envolvem, na plenitude de seus volumes, cores, luzes e sombras. Nos seus últimos trabalhos o artista voltou-se para o passado, buscando, em sua prodigiosa memória visual, nos revelar bichos, coisas, pessoas, lugares que acompanharam seus dias, e que se esvaem nos melancólicos espaços do tempo. Flávio Tavares permanece fiel à sua linguagem. Nesse momento de tantos equívocos, importa mais que nos mostre por onde andam as suas emoções, para nos fazer sentir - gratificados - o que já foi vivido com amor, ternura, ou até mesmo velados desgostos.

HERMANO JOSÉ — Artista Plástico

Por oportuno, é relevante discorrer-se, ainda, a respeito da necessidade de justificativa do preço contratado a comprovar se o contrato celebrado causou ou não prejuízos ao Erário Público. Com efeito, estabelece o inciso III, parágrafo único, art. 26 da Lei $n^{\circ} 8.666 / 93$ :

Parágrafo único. O processo de dispensa, de inexigibilidade ou de retardamento, previsto neste artigo, será instruído, no que couber, com os seguintes elementos:

(...)

III — justificativa do preço.

Esta exigência é decursiva da obrigatoriedade de todo agente público agir de forma transparente, demonstrando sempre os motivos ensejadores à prática de determinado ato administrativo, bem como o contexto fático e jurídico em que se deu sua execução. $O$ preço a ser contratado, em se tratando de aquisições de bens ou serviços pela Administração Pública, deverá respeitar os princípios da economicidade e da razoabilidade, segundo os quais os valores pagos deverão ser justos, ou seja, compatíveis com os praticados no mercado. O fato de se estar falando em inexigibilidade de licitação não afasta a necessidade de comprovação da legitimidade do preço ajustado. Entretanto, os objetos contratados (os quadros adquiridos) certamente não são similares àqueles assinados por outros artistas não consagrados, o que, por si só, já legitimaria o preço pago.

Por tudo o que foi dito não há como se negar a completa regularidade do procedimento de inexigibilidade e do contrato de compra e venda dele decorrente realizados pelo Tribunal de Justiça para aquisição das obras de arte. 


\title{
Sociologia do Direito
}

\author{
Nelson Saldanha
}

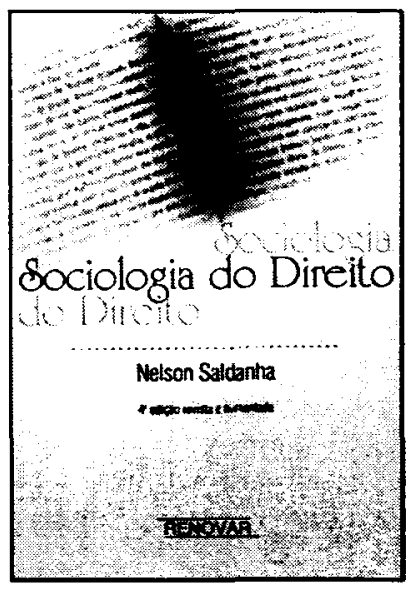

Fundamentado em uma visão sociológica do mundo jurídico e da vida do Direito, de suas formas e conteúdos, o Autor apresenta temas freqũentemente omitidos em obras sobre o assunto, emprestando-lhe aspecto original. Apesar do caráter didático, tendo em vista a inclusão da matéria em várias instituiçōes se ensino superior, a obra reúne grande quantidade de referências bibliográficas, o que a torna de valor, não apenas para estudantes, mas a todos os que desejarem inteirar-se do estudo jurídico sob um prisma sociológico.

Ref. $0210 \quad$ Brochura 291 págs.

Form. 14x21 1999

\section{Temas de Direito Civil}

Gustavo Tepedino

Eis uma obra indispensável para o novo Direito Civil brasileiro que abre as portas do próximo milênio. Trabalho exemplar, é um verdadeiro chamamento à comunhão que a renovada civilística brasileira celebra, rente à vida e ciente de seu compromisso social. Fruto da pesquisa séria e constante, marco dos estudos do Autor, o volume que emerge é um testemunho de uma vitalidade reencontrada no Direito Civil, apta a nela reconhecer esse movimento de renascença intelectual.

Ref. 0197

Form. 16x23

Encadernado 506 págs. 1999

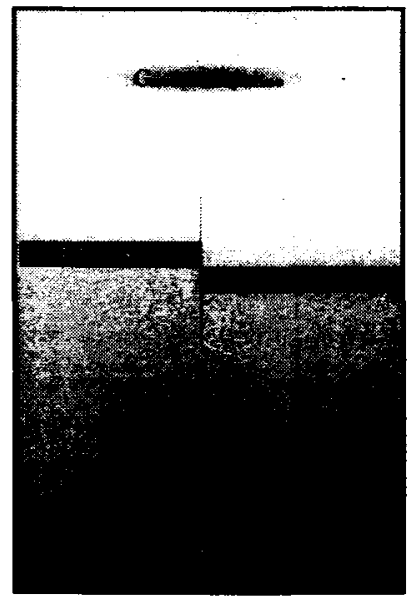

